\title{
Comparison of Urban Forest Inventory \& Management Software Systems ${ }^{1}$
}

Michael G. Andreu, Erin M. Brown, Melissa H. Friedman, Robert J. Northrop, and Mary E. Thornhill ${ }^{2}$

\section{Background}

In 1997, Olig and Miller published $A$ Guide to Street Tree Inventory Software, providing a comparison of software providers, customization options, and data-entry time estimates for each software. After twelve years much of the information is outdated due to the rapid development of new technology and software upgrades. In 2006, the University of Florida held an Urban Forest Inventory Systems Symposium. This meeting brought together a suite of urban forest professionals to share their considerations when selecting tree inventory software systems and how these systems facilitated their management efforts (Andreu et al 2007). During this symposium it became apparent that an updated resource for selecting a tree inventory software system was needed. Coincidentally, in 2007, the US Forest Service published Tree Inventory and Management Software (USFS 2007), which provided a brief one-paragraph description of each of the software systems available at the time.

\section{Introduction}

This extension publication examines many of the tree inventory software systems available as of 2009. It provides up-to-date information about previously existing tree inventory software systems as well as those recently launched. However, the list of software systems provided here is not comprehensive, as we only included companies that we were able to successfully interview. The information provided in this publication has been reviewed and approved by each inventory system software provider. As a result, this synthesis pulls together more details of

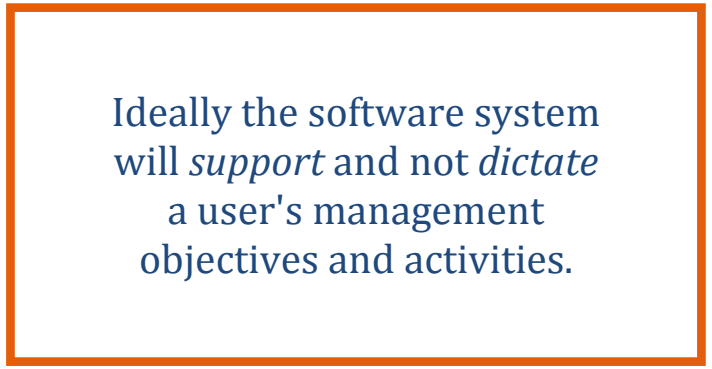

tree inventory software systems than previously available in one document.

When selecting a tree inventory software system, it is important to assess the user's needs and objectives so that the proper system can be chosen. Ideally the software system will support and not dictate a user's management objectives and activities. Below are some factors to consider when selecting a tree inventory software system:

1. This document is FOR226, one of a series of the School of Forest Resources and Conservation Department, Florida Cooperative Extension Service, Institute of Food and Agricultural Sciences, University of Florida. First published: August 2009. Visit the EDIS Web site at http://edis.ifas.ufl.edu.

2. Michael G. Andreu, a ssistant professor; Erin M. Brown, research assistant; Melissa H. Friedman, biological scientist; Robert J. Northrop, extension forester; a nd M ary E. Thornhill, g raduate s tudent; $\mathrm{S}$ chool of Forest R esources a nd C onservation; Institute of Food a nd A gricultural S ciences; University of Florida; Gainesville 32611.

The use of trade names in this publication is solely for the purpose of providing specific information. UF/IFAS does not guarantee or warranty the products named, and references to them in this publication does not signify our approval to the exclusion of other products of suitable composition. Microsoft and Windows are either registered trademarks or trademarks of Microsoft Corporation in the United States and/or other countries.

The Institute of Food and Agricultural Sciences (IFAS) is an Equal Employment Opportunity Institution authorized to provide research, educational information, and other services only to individuals and institutions that function with non-discrimination with respect to race, creed, color, religion, age, disability, gender, sex, sexual orientation, marital status, national origin, political opinions or affiliations. U.S. Department of Agriculture, Cooperative Extension Service, University of Florida, IFAS, Florida A. \& M. University Cooperative Extension Program, and Boards of County Commissioners Cooperating. Millie Ferrer, Interim Dean. 
- What types of questions is the inventory going to answer?

- Who is responsible for managing the urban forest inventory system?

- Are the software and data export files compatible with other software systems that are commonly used?

- How much training time is required and how much does it cost?

- What kind of upgrades and technical support does the software company offer?

For the purposes of comparing the features and capabilities of various tree inventory software systems, we have provided information in four tables. These tables are designed to allow managers to quickly assess which software systems offer the features they desire. Brief summaries, or 'mini spec sheets,' for each inventory system follow to provide additional information, such as typical clients/user types, upcoming upgrades, software costs, technical support, and contact information.

\section{Guide to Tree Inventory Software Comparison Tables}

Table 1 provides a comparison of the features and capabilities of each software system. The Customizable Data Fields and Customizable Reports features indicate which system allows users to tailor the software system design and data format to meet their data collection or analysis needs. The Work Order Generation and Track

Maintenance features allow managers to document and manage tree maintenance and field crew schedules. Some systems include a geographic information system or $\boldsymbol{G I S}$

Component, which allows users to view their tree data and create maps. The Tree Valuation field indicates which systems have a tree valuation component. The Photographs, Sketches or Diagrams field indicates the ability to attach image files to a tree record in the inventory. The Inventory Other Assets field indicates which systems can manage other assets beyond trees (e.g. street signs, park benches, utilities). The Sync with Field Devices field indicates which systems allow users to synchronize their field data collection devices (e.g. personal digital assistant) with their personal computers for data transfer. The Web-based Software field indicates which software operates via the Internet. And lastly, the Network Installation field simply indicates that the software can be installed on a network for multiple users.

Table 2 provides a comparison of the various self explanatory data fields that can be customized: species list, maintenance recommendations, work areas/neighborhoods, and appearance.

Table 3 designates the types of Geographic Information Systems (GIS) components that are utilized by each software system: ESRI-

Compatible, ESRI GIS System, Non-ESRI Mapping or GIS System. Additionally, it provides information about which software systems allow tree attribute data to be modified (Modify Tree Data in GIS Mode), and which systems allow users to alter the spatial coordinates of trees while in the GIS mode (Manually Edit Trees in GIS Mode).

Table 4 illustrates the operating system requirements for each software system: Windows 98, Windows 2000, Windows XP, Windows Vista, Mac OS X, and Linux. The Internet-based column indicates which software systems are only accessible via Web browser. This means that the software system cannot be installed on a local hard drive or intranet, and therefore requires an Internet connection. 
Table 1. Comparison of software capabilities and features.

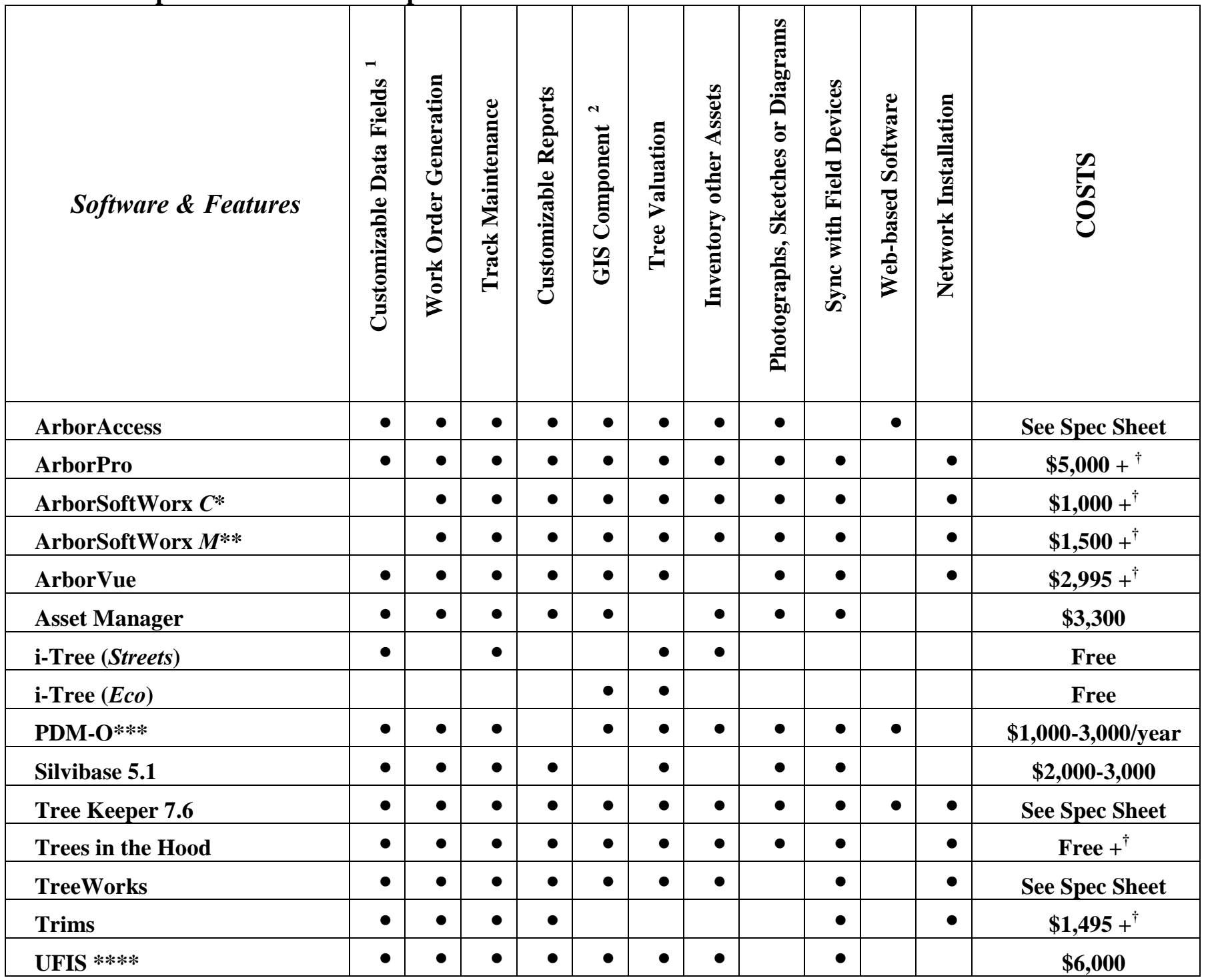

* ArborSoftWorx Commercial

** ArborSoftWorx Municipal

*** Point DataMap-Online

**** Urban Forest Inventory Systems

${ }^{1}$ See Table 2 for a further comparison of customizable data fields.

${ }^{2}$ See Table 3 for further comparisons of GIS features.

${ }^{\dagger}$ The + indicates that there is an annual support package or maintenance fee in addition to the base price. 
Table 2. Comparison of data field customization.

\begin{tabular}{|c|c|c|c|c|c|c|c|c|c|c|c|c|}
\hline $\begin{array}{l}\text { Customizable } \\
\text { Data Fields }\end{array}$ & 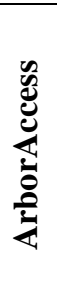 & 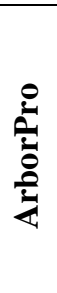 & 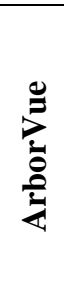 & 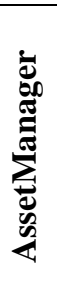 & 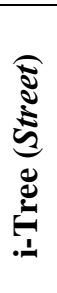 & 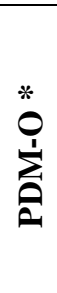 & 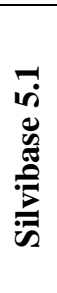 & 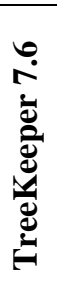 & 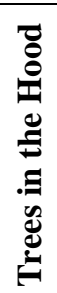 & 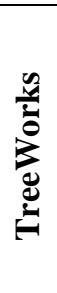 & . & 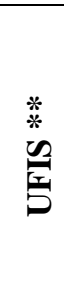 \\
\hline Species List & & $\bullet$ & $\bullet$ & $\bullet$ & $\bullet$ & $\bullet$ & $\bullet$ & $\bullet$ & $\bullet$ & $\bullet$ & $\bullet$ & $\bullet$ \\
\hline Maintenance Recommendations & $\bullet$ & $\bullet$ & $\bullet$ & $\bullet$ & $\bullet$ & $\bullet$ & $\bullet$ & $\bullet$ & $\bullet$ & $\bullet$ & $\bullet$ & $\bullet$ \\
\hline Work Areas/Neighborhoods & $\bullet$ & $\bullet$ & $\bullet$ & $\bullet$ & $\bullet$ & $\bullet$ & $\bullet$ & $\bullet$ & $\bullet$ & $\bullet$ & $\bullet$ & $\bullet$ \\
\hline Appearance (skins) & $\bullet$ & $\bullet$ & $\bullet$ & $\bullet$ & & $\bullet$ & & & $\bullet$ & $\bullet$ & & $\bullet$ \\
\hline
\end{tabular}

* Point DataMap-Online

** Urban Forest Inventory Systems

Table 3. Comparison of GIS components.

\begin{tabular}{|c|c|c|c|c|c|c|c|c|c|c|c|c|}
\hline GIS Components & 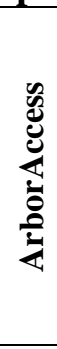 & 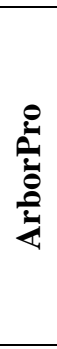 & 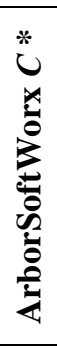 & 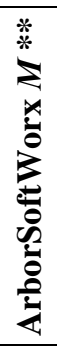 & 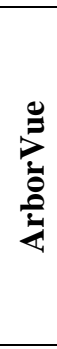 & 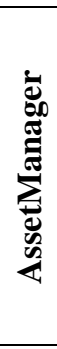 & 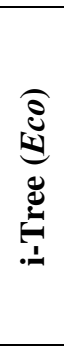 & 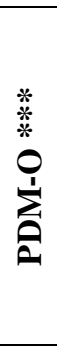 & 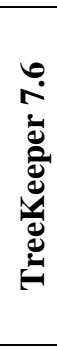 & 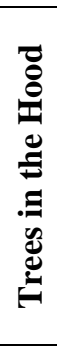 & 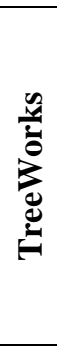 & 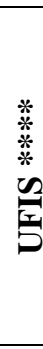 \\
\hline ESRI Compatible & $\bullet$ & $\bullet$ & $\bullet$ & $\bullet$ & $\bullet$ & $\bullet$ & & $\bullet$ & $\bullet$ & $\bullet$ & $\bullet$ & $\bullet$ \\
\hline ESRI GIS System & & & & & $\bullet$ & $\bullet$ & & & $\bullet$ & & $\bullet$ & \\
\hline $\begin{array}{l}\text { Non-ESRI Mapping or } \\
\text { GIS System }\end{array}$ & - & $\bullet$ & - & $\bullet$ & & & $\bullet$ & $\bullet$ & & & & - \\
\hline Modify Tree Data in GIS Mode & & $\bullet$ & & & $\bullet$ & $\bullet$ & & $\bullet$ & $\bullet$ & $\bullet$ & $\bullet$ & $\bullet$ \\
\hline $\begin{array}{l}\text { Manually Edit Trees in } \\
\text { GIS Mode }\end{array}$ & & - & & & $\bullet$ & $\bullet$ & & $\bullet$ & $\bullet$ & - & - & • \\
\hline
\end{tabular}

* ArborSoftWorx Commercial

** ArborSoftWorx Municipal

*** Point DataMap-Online

**** Urban Forest Inventory Systems 
Table 4. Comparison of Operating Systems (OS) Compatibility.

\begin{tabular}{|c|c|c|c|c|c|c|c|}
\hline Software OS Requirements & 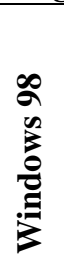 & 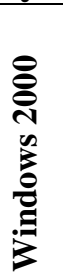 & 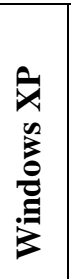 & 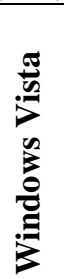 & $\begin{array}{l}x \\
\mathscr{0} \\
0 \\
y \\
\tilde{z}\end{array}$ & 害 & 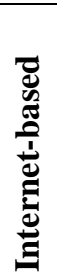 \\
\hline ArborAccess & & & & & & & $\bullet$ \\
\hline ArborPro & $\bullet$ & $\bullet$ & $\bullet$ & $\bullet$ & & & \\
\hline ArborSoftWorx $C^{*}$ & $\bullet$ & $\bullet$ & $\bullet$ & $\bullet$ & & $\bullet$ & \\
\hline ArborSoftWorx $M^{* *}$ & $\bullet$ & $\bullet$ & $\bullet$ & $\bullet$ & & $\bullet$ & \\
\hline ArborVue & & & $\bullet$ & $\bullet$ & & & \\
\hline Asset Manager & $\bullet$ & $\bullet$ & $\bullet$ & $\bullet$ & & & \\
\hline i-Tree (Street) & & $\bullet$ & $\bullet$ & & & & \\
\hline i-Tree $(E c o)$ & & $\bullet$ & $\bullet$ & & & & \\
\hline PDM-O*** & & & & & & & $\bullet$ \\
\hline Silvibase 5.1 & & $\bullet$ & $\bullet$ & & & & \\
\hline Tree Keeper 7.6 & & & & & & & $\bullet$ \\
\hline Trees in the Hood & $\bullet$ & $\bullet$ & $\bullet$ & $\bullet$ & $\bullet$ & & \\
\hline TreeWorks & & $\bullet$ & $\bullet$ & $\bullet$ & & & \\
\hline Trims & & • & $\bullet$ & $\bullet$ & & & \\
\hline UFIS $* * * *$ & $\bullet$ & $\bullet$ & $\bullet$ & & & & \\
\hline
\end{tabular}

* ArborSoftWorx Commercial

** ArborSoftWorx Municipal

*** Point DataMap-Online

**** Urban Forest Inventory Systems

The following pages include

Individual Tree Inventory Software Spec Sheets

For detailed technical specifications, visit vendor Web sites. 


\section{ArborAccess $^{\circledR}$}

Introduction to Software

ArborAccess Online is an internet-driven software developed by tree care professionals at West Coast Arborists, Inc. (WCA). It is accessible only to WCA clients, who are primarily municipalities in California. ArborAccess can be customized to the needs of each WCA client. According to West Coast Arborists, it can store an unlimited number of tree records.

\section{Services \\ * Tree Inventories \\ * Tracks Maintenance History \\ * GIS Mapping \\ * Budget Projections \\ * Basic Tree Appraisals}

\section{Additional Information}

An upgraded version of ArborAccess is projected to be available by 2009. This version will be an ArcIMS compatible system. It will allow users to interact with and modify the inventory data through the database and/or the GIS maps via the Internet.

\section{Operating System Requirements}

Internet Connection and Web browser (e.g. Internet Explorer 5.5 or greater)—ArborAccess does not require additional hardware, memory, or software; as it is stored on WCA's server and functions remotely.

\section{Software Costs}

The cost of ArborAccess is included in municipal contracts. Contact WCA for further details.

\section{Technical Support}

WCA offers unlimited training and support to their clients. Periodic workshops are offered for larger groups or after software upgrades have occurred. WCA's Area Managers are also available to assist clients on an as-needed basis.

\section{Contact Information}

West Coast Arborists, Inc. 2200 East Via Burton Street

Anaheim, CA 92806

Phone: 1-800-521-3714

Fax: 1-714-956-3745

Email: info@wcainc.com

Web site: http://www.wcainc.com

\section{ArborPro}

\section{Introduction to Software}

ArborPro was developed and is distributed by ArborPro Management Software. ArborPro is a tree management software designed to manage trees, the landscape, and physical assets. It is used by municipalities, parks, campuses, and golf courses. ArborPro has been tested and is able to store over a million tree records.

\section{Services \\ * Tree Inventories \\ * Tracks Maintenance History \\ * GIS Mapping \\ * Tree Hazard Assessments \\ * Crew Management Program \\ * Budgeting}

\section{Additional Information}

ArborPro has a new measuring tool that allows clients to see the distance between two assets on the map. For example, planting distance between trees, distance from trees to park assets or buildings, and tree canopy spreads can be measured.

\section{Operating System Requirements}

Windows 98, Windows 2000, Windows XP, or Windows Vista

\section{Software Costs}

The base price for ArborPro is $\$ 5,000$.

\section{Technical Support}

After the initial purchase of ArborPro, 2 eight-hour training sessions are available free of charge: (1) initial training session, (2) focused training session. ArborPro also offers an optional annual support package (includes upgrades) for $\$ 1,500$.

\section{Contact Information}

ArborPro, Inc.

P.O. Box 4096

Newport Beach, CA 92661-4096

Phone: 1-877-844-DATA (3282)

Fax: 1-714-694-1981

Email:_info@arborprousa.com

Web site: http://www.arborprousa.com 


\section{ArborSoftWorx $^{\circledR}$ Commercial}

Introduction to Software

ArborSoftWorx was developed and is distributed by Creative Automation Solutions, Inc. ArborSoftWorx Commercial is primarily a customer and business management software. It is designed for arbor, landscape, and plant health care companies.

\section{Services \\ * Customer Relationship Management \\ * Business Management (accounting, invoicing, and receivables) \\ * Scheduling, Routing, and Mapping of Field Crews \\ * Chemical Tracking and Reporting \\ * Property Inventory \\ * Company Asset Management \\ * Personnel Management}

\section{Additional Information}

ArborSoftWorx can support single office operations and/or multiple branch offices. Data and reports can be exported into all Microsoft, Corel, and Lotus Office suites. Creative Automation Solutions, Inc. also offers data conversions into i-Tree.

\section{Operating System Requirements}

Windows 98, Windows 2000, Windows XP, Windows Vista, or Linux

\section{Software Costs}

The base price for a single user is $\$ 1,000$. Additional features are available; the price will vary depending on how many additional features the client requests. Contact a sales associate for network system prices.

\section{Technical Support}

On-site installation and training is available. An additional support package that includes upgrades is available to clients but the cost varies depending on the number of computers.

\section{Contact Information}

Creative Automation Solutions, Inc.

10500 Old Court Rd.

Woodstock, MD 21163

Phone: $\quad 1-800-49-A R B O R$ (2-7267) or

$$
1-410-461-5858
$$

Fax: 1-410-465-3593

Email: $\quad$ Sales@ArborSoftWorx.com

Web site: http://www.arborsoftworx.com

\section{ArborSoftWorx $^{\circledR}$ Municipal}

\section{Introduction to Software}

ArborSoftWorx was developed by and is distributed by Creative Automation Solutions. ArborSoftWorx Municipal is an inventory and asset management software. It is designed for counties, cities, townships, campuses, parks, and estates.

\section{Services \\ * Tree Inventories \\ * Track Maintenance History \\ * Track Service Calls \\ * Scheduling, Routing, and Mapping of Field Crews \\ * Tree Risk and Hazard Assessments \\ * Chemical Tracking and Reporting \\ * GIS Mapping \\ * Budgeting}

\section{Additional Information}

Data and reports can be exported into all Microsoft, Corel, and Lotus Office suites. Creative Automation Solutions, Inc. also offers data conversions into i-Tree.

\section{Operating System Requirements}

Windows 98, Windows 2000, Windows XP, Windows Vista, or Linux

\section{Software Costs}

The base price for a single user is $\$ 1,500$. Contact a sales associate for network system prices.

\section{Technical Support}

On-site installation and training is available.

\section{Contact Information}

Creative Automation Solutions, Inc.

10500 Old Court Rd.

Woodstock, MD 21163

Phone: 1-800-49-ARBOR (2-7267) or

Fax: $\quad 1-410-461-5858$

Email: $\quad$ Sales@ArborSoftWorx.com

Web site: http://www.arborsoftworx.com 


\section{ArborVue}

Introduction to Software

ArborVue was developed and is distributed by The Laurus Group. It is a tree inventory management software designed for urban tree managers. According to The Laurus Group, ArborVue can store an unlimited number of tree records.

\section{Services \\ * Tree Inventories \\ * Track Maintenance History \\ * GIS Mapping \\ * Budgeting \\ * Tree Damage Evaluations}

\section{Additional Information}

ESRI's ArcGIS Engine Runtime and/or ArcPad 7 are included in the ArborVue software package.

Therefore, ArborVue clients do not have to purchase additional ESRI products to run this software.

ArborVue's database uses SQL Server/SQL Server Express. SQL Server Express is included with the purchase of ArborVue (supports up to 10 concurrent users) but if more users are needed, SQL Server is available. Database hosting is also available for clients who do not wish to maintain SQL Server/SQL Server Express.

\section{Operating System Requirements}

Windows 200, Windows XP, or Windows Vista

\section{Software Costs}

The base price for ArborVue is $\$ 2,995$.

\section{Technical Support}

The first year of technical supports and upgrades are included in the base price. Afterwards, it is $\$ 495 /$ year for additional support and future upgrades. ArborVue offers multiple upgrades each year.

\section{Contact Information}

The Laurus Group, LLC. 4912 Bayshore Drive

Seneca, SC 29672

Phone: $\quad 1-864-654-8733$

Fax: $\quad$ 1-864-654-8889

Email:_arborvueinfo@arborvue.com

Web site: http://www.arborvue.com

\section{Asset Manager}

\section{Introduction to Software}

Asset Manager was developed and is distributed by Davey Resource Group. Asset Manager is a mapbased management software designed to help municipalities, golf courses, college campuses, and even amusement parks to manage a variety of assets. Some of these assets include: trees, planting areas, turf areas, greens, fairways, drains, irrigation lines, hydrants, and valves.

\section{Services \\ * Tree Inventories \\ * Track Maintenance History \\ * GIS Mapping \\ * Budgeting}

\section{Additional Information}

Asset Manager stores data in ESRI shape files. Data can also be exported to a comma delimited text file, which can then be imported to spreadsheet and database applications.

\section{Operating System Requirements}

Windows 98, Windows 2000, Windows XP, or Windows Vista

\section{Software Costs}

The base price for Asset Manager is $\$ 3,300$.

\section{Technical Support}

There are two options for technical support: 1) a one day on-site training is available for $\$ 1,300$, or 2 ) one year of unlimited support is available for $\$ 1,000$.

\author{
Contact Information \\ Davey Resource Group \\ 1500 N. Mantua St. \\ PO Box 5193 \\ Kent, OH 44240-5193 \\ Phone: $\quad 1-800-828-8312$ \\ Fax: 1-330-673-0860 \\ Email: gis@davey.com \\ Web site: http://www.davey.com/software
}




\section{i-Tree}

Introduction to Software

i-Tree was developed by the USDA Forest Service, Davey Tree Expert Co., National Arbor Day

Foundation, Society of Municipal Arborists, and the International Society of Arboriculture. In the public domain and freely accessible, i-Tree is a software suite that allows managers to analyze and assess the environmental and aesthetic benefits of their urban and community forests. The suite contains two urban forest analysis tools: Eco (formerly UFORE) for ecosystem level assessments of the entire urban forest; and Street (formerly STRATUM) for municipal street tree assessments alone.

\section{Services \\ * Tree Inventories \\ * Track Maintenance History \\ * Tree Hazard and Risk Assessments \\ * Budgeting \\ * Insect and Disease Assessments \\ * Environmental and Aesthetic Benefit Assessments \\ * Ice/Wind Storm Assessments}

\section{Additional Information}

Street is designed for analyzing street tree populations, not the entire urban forest. Street quantifies the annual environmental and aesthetic benefits, as well as the property value increase from street trees. It can be used to compare canopy cover for different neighborhoods, species diversity, tree conflicts and maintenance needs, as well as species performance. New or existing inventories can be formatted for Street compatibility.

Eco is designed for analyzing the entire urban forest at the ecosystem level. Eco calculates urban forest structure, function, and value using area-based field sampling combined with local air quality and weather information. The urban forest can be examined at any scale and can be stratified (e.g. land-use types).

$\mathrm{i}$-Tree is on a continuous development cycle. In spring of 2009, i-Tree 3.0 was released, enhancing

functionality, uniformity, and integration for improved utility.

Operating System Requirements

Windows XP or Windows Vista

\section{Software Costs}

i-Tree is a public domain software, distributed at no cost.

\section{Technical Support}

i-Tree offers support online, on the phone, or through a user forum. The i-Tree User Forum is a moderated discussion forum that allows users to seek solutions to technical questions, communicate their experiences, and/or view frequently asked questions (FAQs).

\section{Contact Information}

i-Tree

1500 N. Mantua St.

Kent, OH 44240

Phone:

1-877-574-8733

Email: info@itreetools.org

Web site: http://www.itreetools.org

\section{PDM-O $^{\mathrm{TM}}$ - Point DataMap Online}

\section{Introduction to Software}

PDM-O was developed and is distributed by

StrataPoint, Inc. PDM-O is an internet-driven grounds and tree management software developed for municipalities, golf courses, and campuses. Since it is a web-based technology it can accommodate multiple concurrent users. According to StrataPoint, PDM-O can also store an unlimited number of tree records.

\section{Services \\ * Tree Inventories \\ * Track Maintenance History \\ * GIS Mapping \\ * Tree Risk Assessment \\ * Tree Crown/Shade Profiling \\ * Chemical Tracking \\ * Irrigation Management}

\section{Additional Information}

PDM-O facilitates turfgrass management by providing managers with a profile of each tree's crown and its shade profile.

\section{Operating System Requirements}

Internet connection and Web browser (Internet-based software)

\section{Software Costs}

Clients can subscribe to PDM-O for $\$ 1,000-\$ 3,000$

per year. Contact a sales associate for more

information. 


\section{Technical Support}

Free online and phone technical support is available to subscribers.

\section{Contact Information}

$\begin{array}{ll}\text { Phone: } & 1-651-322-4000 \\ \text { Fax: } & 1-651-322-5747 \\ \text { Email: } & \text { sales@stratapointinc.com or } \\ & \text { info@stratapointinc.com }\end{array}$

Web site: http://www.stratapointinc.com

\section{Silvibase 5.1}

\section{Introduction to Software}

Silvibase 5.1 was developed and is distributed by Natural Resource Planning Services, Inc. Silvibase 5.1 operates on a run-time version of Microsoft Access and is intended for small municipalities that do not need additional capabilities, such as GIS.

\section{Services \\ * Tree Inventories \\ * Maintenance Plans \\ * Production Monitoring}

\section{Additional Information}

Tree data can be directly exported into ArcView. Note: Silvibase 5.1 does not have a built-in mapping component. Additionally, it is not necessary to purchase Microsoft Access, since Silvibase 5.1 operates on a run-time version of Microsoft Access. Silvibase 5.1 also works with Windows CE and ArcPad on portable field devices.

\section{Operating System Requirements}

Windows 2000 or Windows XP

\section{Software Costs}

The base price for Silvibase 5.1 ranges from $\$ 2,000$ $\$ 3,000$, which includes the initial training and set-up.

\section{Technical Support}

Available via phone and email, free of charge.

\section{Contact Information}

Natural Resource Planning Services, Inc. 5700 SW $34^{\text {th }}$ St. Suite 324

Gainesville, FL 32608

Phone: $\quad$ 1-352-378-8966

Fax: 1-352-336-4877

Email:_ DaveF@nrpsforesters.com

Web site: http://www.nrpsforesters.com

\section{TreeKeeper $^{\circledR} 7.6$}

\section{Introduction to Software}

TreeKeeper 7.6 was developed and is distributed by Davey Resource Group. TreeKeeper 7.6 is an internetdriven tree management software intended for municipalities. It is a web-based technology and can be accessed from home, offices, and anywhere with internet capabilities.

\section{Services \\ * Tree Inventories \\ * Tracks Maintenance History \\ * Tracks Service Calls \\ * GIS Mapping \\ * Tree Hazard Assessments and Valuations}

\section{Additional Information}

Davey Resource Group offers clients an unlimited amount of data field customization, as well as a wide range of report customization. TreeKeeper 7.7 is projected to be released by the time this document has been published. A fully functioning demonstration of TreeKeeper 7.6 is available at treekeeperonline.com

\section{Operating System Requirements}

Internet connection and Web browser (Internet-based software)

\section{Software Costs (3 options for deployment)}

1. Standalone - TreeKeeper ${ }^{\circledR} 7.6$ is installed locally on a PC and can only be accessed on this computer. There is a one time cost of $\$ 4,600$ for small cities (pop. $<30,000$ ), and $\$ 7,700$ for larger cities (pop. $>30,000$ ). Note: There is not a concurrent user option with this method and clients are responsible for their data. Upgrades range in cost.

2. Network-TreeKeeper ${ }^{\circledR} 7.6$ is deployed on the client's server, accessed via the internet or intranet. There is a one time cost of $\$ 12,000$. Note: This option allows for concurrent users and in the longterm (more than 6 years) it is less expensive than the subscription. Clients are responsible for their data and upgrades range in cost.

3. Subscription - TreeKeeper ${ }^{\circledR} 7.6$ is accessed through Davey Resource Group's Web server. In the short-term this is the least expensive option, costing \$2100 for a year subscription. There is a 3year subscription available for $\$ 5,250$. With the subscription method, data is backed up every night by Davey Resource Group and upgrades are free. 


\section{Technical Support}

There are two options for technical support: 1) a oneday on-site training is available for $\$ 1,300$, and 2) one year of unlimited support is available for $\$ 1,000$.

\section{Contact Information}

Davey Resource Group

1500 N. Mantua St.

PO Box 5193

Kent, OH 44240-5193

Phone: $\quad 1-800-828-8312$

Fax: $\quad$ 1-330-673-0860

Email: gis@davey.com

Web site: http://www.davey.com/software

\section{Trees in the Hood ${ }^{\mathrm{TM}}$}

\section{Introduction to Software}

Trees in the Hood was developed and is distributed by Natural-Path Urban Forestry Consultants. It is a free shareware designed to assist small communities, parks, golf courses, and campuses manage their trees. Trees in the Hood is based in Microsoft Access. According to Natural-Path Urban Forestry Consultants, it can manage an unlimited number of tree records.

\section{Services \\ * Tree Inventories \\ * Track Maintenance History \\ * GIS Mapping \\ * Production Monitoring \\ * Tracks Field Crews}

\section{Additional Information}

The data fields for Trees in the Hood are set up to match Street (part of the i-Tree suite). Trees in the Hood offers tree analysis by family, genus, and species. Trunk formula appraisals are based on individual chapter parameters from the Council of Tree and Landscape Appraisers (CTLA).

\section{Operating System Requirements}

Windows 98, Windows 2000, Windows XP, Windows Vista, or Mac OS X

\section{Software Costs}

The software is free shareware. However, there is a set-up cost that varies depending on the client's needs. Contact the owner, Mark Duntemann, for more information.

\section{Technical Support}

Technical support is free for two years; subsequently there is a non-mandatory charge of $\$ 250$ per year.

\section{Contact Information \\ Natural Path Urban Forestry \\ PO Box 1753 \\ Oak Park, IL 60304 \\ Phone: 1-773-699-7284 \\ Email: $\quad$ natpath@earthlink.net \\ Web site: http://www.naturalpathforestry.com}

\section{TreeWorks ${ }^{\mathrm{TM}}$}

\section{Introduction to Software}

TreeWorks was developed and is distributed by The Kenerson Group. TreeWorks is a tree management software developed by a collaboration of GIS specialists and arborists. It is an extension to ArcGIS 9.x Desktop and ArcPad. TreeWorks is commonly used by municipalities, campuses and military bases. It has been shown to store over 500,000 tree records.

\section{Services \\ * Tree Inventories \\ * Track Maintenance History \\ * GIS Mapping \\ * Tree Risk and Hazard Assessment \\ * Tree Valuations \\ * Track Service Calls \\ * Production Monitoring}

\section{Additional Information}

TreeWorks is an extension (toolbar) that operates inside of ArcGIS, therefore clients can use all of the ArcGIS functions and base layers to perform complex analysis. A check-in/check-out function allows clients to transfer their entire or select dataset(s) to their field devices. Furthermore, TreeWorks is fully customizable software - all data fields and reports can be modified to meet the client's needs.

\section{Operating System \& Special Requirements} Compatible with Windows 2000, Windows XP, or Windows Vista; ArcGIS is required.

\section{Software Costs}

The base price of TreeWorks is determined on a case by case basis depending on the customer's needs, contact a sales associate for more information. The base price includes free updates for the first year. Afterwards there is an annual maintenance fee of $\$ 600$. This maintenance fee includes technical support 
and the cost of upgrades. TreeWorks provides clients with at least two upgrades each year.

\section{Technical Support}

On-site training is available, as well as online and phone technical support.

\section{Contact Information}

The Kenerson Group

2342 Main Street

Athol, MA 01331

Phone: 1-978-249-6495

Fax: 1-978-249-4784

Email: info@kenersongroup.com

Web site: http://www.kenersongroup.com

\section{TRIMS Tree Inventory}

\section{Introduction to Software}

TRIMS Tree Inventory was developed and is distributed by TRIMS Software International, Inc. It is a tree inventory software developed for municipalities, golf courses, parks, businesses, and campuses. According to TRIMS Software International, it can store an unlimited number of tree records.

\section{Services \\ * Tree Inventories \\ * Track Maintenance History \\ * Production Monitoring \\ * Scheduling Field Crews}

\section{Additional Information}

TRIMS Tree Inventory provides two different tree inventory systems: 1) Municipal Street Tree Inventory - trees are identified by the street address, and 2) Golf Course \& Park Tree Inventory - trees are identified by a grid location or map. TRIMS Tree Inventory also comes with a 32-bit Open Database Connectivity allowing tree data files to be exported into Microsoft Excel, Access, and Word. TRIMS releases at least one upgrade per year to incorporate new technological and industry advances.

\section{Operating System Requirements}

Windows 2000, Windows XP, or Windows Vista

\section{Software Costs}

TRIMS Tree Inventory standard version comes as a 2User Network System, priced at $\$ 1,495$. There is an annual fee of $\$ 345$ after the first year. Individual or multiple user and site licenses are available. Contact a sales associate for more information.

\section{Technical Support}

Step-by-step installation instructions are provided for standalone systems, network workstations, and servers. The purchase of TRIMS Tree Inventory includes the first year of technical support, customer service and upgrades. After the first year, there is a $\$ 345$ annual fee to continue technical support and upgrades for the standard 2-user network systems and a $\$ 445$ fee for multi-user and network license systems.

\section{Contact Information}

TRIMS Software International, Inc. 8987 W. Olive, \#117, PMB 68

Peoria, AZ 85345

Phone: $\quad 1-800-608-7467$ or $1-623-266-1943$

Fax: 1-602-266-1945

Email: info@trims.com

Web site: http://www.trims.com

\section{Urban Forest Inventory System (UFIS)}

\section{Introduction to Software}

The UFIS was developed by Natural Resource Consulting, Inc. and is now distributed by its sister company, Natural Resource Technologies, LLC. According to Natural Resource Consulting, Inc. it can store an unlimited number of tree sites.

\section{Services \\ * Tree Inventories \\ * Track Maintenance History \\ * GIS Mapping \\ * Production Monitoring}

\section{Additional Information}

UFIS mapping features operate on a MapInfo platform. Existing maps can be imported from AutoCAD, ArcView, and other popular formats. Data can be exported into the i-Tree suite for further analysis.

\section{Operating System Requirements}

Windows 98, Windows 2000, or Windows Vista

\section{Software Costs}

The base price for UFIS is $\$ 6,000$. The cost for upgrades varies depending on the product and client's needs. Contact a sales representative for more information. 


\section{Technical Support}

Technical support is available by phone or email at support@nrtech.com.

\section{Contact Information}

Natural Resource Technologies, L.L.C.

PO Box 780603

Tallassee, Alabama 36078

Phone: $\quad 1-888-848-2146$ or $1-334-252-0744$

Fax: $\quad$ 1-334-252-0654

Email: info@nrtech.com or sales@nrtech.com

Web site: http://www.nrtech.com

\section{Acknowledgements}

The authors would like to thank the companies listed above for participating in our interviews about their systems, and for providing us with much of the information for the content of this publication.

\section{References}

Andreu, M.G., R.J. Northrop, and M.H. Friedman. 2007. Proceedings of the urban forest inventory systems symposium, University of Florida - Plant City Campus Dec. 14, 2006. Seffner FL:

Hillsborough County Extension - producer B. Lofland. (Audiovisual Material 3 Disc set.).

Olig, G.A and R.W. Miller. 1997. A Guide to Street Tree Inventory Software. http://www.na.fs.fed.us/ spfo/pubs/uf/streettree/toc.htm (accessed 3/6/2009).

U.S. Forest Service. 2007. Tree Inventory and Management Software. http://www.na.fs.fed.us/ urban/inforesources/inventory/InventorySoftware ListDetails.pdf (accessed 3/6/2009). 